\section{A is for atom}

\section{John Durant}

Science Matters: Achieving Scientific Literacy.By Robert M. Hazen and James Trefil. Doubleday: 1991. Pp.294. $\$ 19.95$.

IN the midst of the Gulf War, US President George Bush took time out to greet the American Association for the Advancement of Science (AAAS), gathered in Washington for its annual meeting. Having pointed out that the US budget included substantial funding increases for mathematics and science eduction, President Bush added that "All sectors of society must recognize the importance of scientific literacy and strive to achieve it".

Scientific literacy is a buzz phrase in American educational circles. It stands for what the general public ought to know about science, and its widespread use reflects concern about the performance of the American educational system. In 1987, the English Professor E. D. Hirsch Jr captured this concern in his best-selling book: Cultural Literacy: What Every American needs to Know (Random House, 1987). Hirsch argued that the unity of American culture depended upon a common stock of generally shared knowledge, which he listed in the form of some 5,000 essential names, phrases, dates and concepts covering the entire world of learning.

In drawing up his list, Hirsch called upon the services of the physicist James Trefil. Trefil took advice from colleagues about the key concepts and facts that were "truly essential to a broad grasp of a major science". The result was several hundred items, ranging from 'absolute zero', through 'mutation', 'nuclear fission' and (amazingly) 'ontogeny recapitulates phylogeny', to 'Y chromosome'. In 1988, the list was expanded into a Dictionary of Cultural Literacy (Houghton-Mifflin, 1988). Starting out from the same concern "to provide only the constellations of basic facts and concepts that you need to understand the scientific issues of the day", Trefil and Earth scientist Robert Hazen attempt to review the world of science in 18 synoptic chapters. The first chapter is entitled 'Knowing', and deals with the idea that the universe is regular and predictable. Then come chapters on everything from energy and electricity to evolution and ecosystems.

Reviewing all of the natural sciences between one set of covers is a daunting task, but Hazen and Trefil approach it with relish. Throughout, they concentrate on key ideas and principles and avoid technical details. They use clearly headed sections to organize their material, and from time to time they highlight fundamental principles in large bold print. For example, chapter 5 on quantum mechanics is introduced with the emboldened statement that, "Everything particles, energy, the rate of electron spin comes in discrete units, and you can't measure anything without changing it".

I share Hazen's and Trefil's enthusiasm for equipping the general public to make sense of the scientific issues of the day, I admire their synoptic grasp of the natural sciences, and I recognize their considerable skill in conveying the broad outlines of science in clear, nontechnical prose. Nevertheless, I have two major reservations about Science Matters. First, the book reflects its authors' disciplinary backgrounds in being too heavily weighted in favour of the physical sciences (14 chapters) and against the life sciences (four chapters). Even worse, it contains virtually nothing about the single area of science that is unquestionably of most direct relevance to the public: medical science.

Second, Science Matters is almost entirely taken up with a summary of the well-established findings of science. It devotes just one page to the scientific method, and just three pages to scientists. The account of scientific method is woefully inadequate, whereas the discussion of scientists is largely taken up with bizarre caricatures of the people who work in different disciplines. Thus, "For some reason many physicists, particularly those in universities, seem to enjoy appear-

\section{Articles of faith}

\section{George Marsden}

\section{Can Scientists Believe? Some Examples of the Attitude of Scientists to Religion. By Sir Nevill Mott. James and James: 1991 Pp. 182. £21, \$40.}

For about a century in western civilization, roughly from the 1860 s to the 1960 s, the belief became widely held that scientific thinking was at odds with Christianity. Although, as a number of the authors of $\mathrm{Can}$ Scientists Believe? point out, this notion rested on a dogmatic conception of scientific knowledge that is now generally considered passé, the idea of an inherent conflict between science and religion has persisted.

In fact, of course, many scientists believe in Christianity and other religions. In the West this is particularly true in the highly religious United States, where over a fourth of scientists are active in churches and half describe themselves as religious. These percentages are not as high for the American public generally; but contrary to some popular belief, scientists are considerably more likely to be religious than are social scientists or humanist academics. So, even though rates of religious practice are much lower in most other western nations, the title question of this collection Can Scientists Believe? has an empirical answer.

Nonetheless, interest persists in this volume's main theme of how believing scientists relate their faith. Sir Nevill Mott's own resol- ing sloppy and disheveled - always the ones without ties at faculty meetings"; whereas biologists are "the only group of scientists who routinely wear white lab coats".

Caricatures such as these do nothing to assist the general public in coming to terms with science; on the contrary, they merely perpetuate the myth that scientists are very peculiar people. But more serious even than this is the fact that Hazen and Trefil present science as a vast edifice of unproblematic knowledge built up by the routine application of 'the scientific method'. This view ignores the methodological diversity of science, as well as the difficulties that arise from scientific ignorance, uncertainty and controversy.

Science Matters is supposed to enable nonscientists to make sense of the scientific issues of the day. But the scientific issues of the day are real-life questions in which reallife people debate matters that are technically and/or socially controversial. Because it ignores this real world of scientific practice, Science Matters provides only a part of what nonscientists need to achieve scientific literacy.

John Durant is at the Science Museum Library, Exhibition Road, South Kensington, London SW7 5NH, UK.

ution of the issue arose from being reassured by a vicar that one could be active in the Anglican Church without literally believing its creeds. But only a few of the other 14 contributors to this volume share the Cambridge physicist's strategy of resolving the problem by broadening the definitions of Christianity. Rather, most reflect on the implications of their scientific knowledge for a rather traditional faith, Protestant, Catholic or in one case Jewish. V. Ya. Frenkel, Professor of the History of Science, Leningrad, is the one contributor who takes a very dim, virtually comtean, view of religion. He remarks that he only ever met one highly intelligent man, a mathematician, who was religious. (The contrast to the number of religious scientists in the United States suggests the degree to which such issues are not decided merely on an intellectual basis.)

Wide diversity of opinion is the most striking general feature of the essays by believing scientists. No reader could be happy with all the contributions because a number contradict each other (as on whether the anthropic principle is of merit). Also a few are little more than impressionistic personal testimonies. Nonetheless, many others are valuable reflections on the relation of science to faith. So almost any reader interested in the topic is likely to find enough to make this a worthwhile volume.

One recurring theme is that science and theology represent two complementary ways of looking at reality. As Richard Bube of Stanford puts it, theology asks "who?" and science asks "why?" Several also note that scientific knowledge is nonetheless a lot 